\title{
Elevated mercury exposure in communities living alongside the Inanda Dam, South Africa
}

\author{
Vathiswa Papu-Zamxaka, ${ }^{\star a}$ Angela Mathee, ${ }^{a b c}$ Trudy Harpham, ${ }^{d}$ Brendon Barnes, ${ }^{b}$ Halina Röllin, ${ }^{a e}$ \\ Michal Lyons, ${ }^{d}$ Wikus Jordaan ${ }^{f}$ and Marthinus Cloete ${ }^{f}$
}

\author{
Received 24th August 2009, Accepted 27th October 2009 \\ First published as an Advance Article on the web 24th November 2009 \\ DOI: $10.1039 / b 917452 d$
}

\begin{abstract}
Mercury is a persistent heavy metal that has been associated with damage to the central nervous system, including hearing and speech impairment, visual constriction and loss of muscle control. In aquatic environments mercury may be methylated to its most toxic form, methyl-mercury. In 1990 concerns were raised over mercury contamination in the vicinity of a mercury processing plant in KwaZulu-Natal, South Africa. Mercury waste was reported to have been discharged into the Mngceweni River, situated in close proximity to the plant. The Mngceweni River joins the uMgeni River, which in turn flows into the Inanda Dam, along the banks of which several villages are located. This study evaluated the mercury levels in river and dam sediments, fish from the Inanda Dam and hair samples collected from residents of three villages along the banks of the Inanda Dam. The study results showed that $50 \%$ of the fish samples and $17 \%$ of hair samples collected from villagers had mercury concentrations that exceeded guideline levels of the World Health Organization. Mercury concentrations in $62 \%$ of the river sediment samples collected in close proximity to the former mercury processing plant exceeded the level at which remedial action is required according to legislation in the Netherlands. These preliminary findings give reasons for concern and should be used as a baseline for further investigations.
\end{abstract}

\section{Introduction}

Mercury is a persistent toxic metal that originates from both natural and anthropogenic sources, and has been identified as a priority global environmental contaminant. ${ }^{1}$ Once deposited into aquatic environments, mercury may become methylated to its most toxic form, methyl-mercury, which is biologically available. ${ }^{2}$ Methyl-mercury is a neurotoxin and has the ability to cross the blood-brain and placental barriers. ${ }^{3}$ Exposure during foetal development may cause severe mental retardation,

${ }^{a}$ South African Medical Research Council, PO Box 87373, Houghton, 2041, South Africa. E-mail: vathiswa.papu@mrc.ac.za; Fax: +27 11642 6832; Tel: +27112746075

${ }^{b}$ University of the Witwatersrand, Johannesburg, South Africa

'University of Johannesburg, Johannesburg, South Africa

${ }^{d}$ London South Bank University, London, United Kingdom

${ }^{e}$ University of Pretoria, Pretoria, South Africa

${ }^{f}$ Council for Geoscience, Pretoria, South Africa long-term disabilities, birth defects and foetal death. ${ }^{4}$ In children and adults, chronic exposure may damage the nervous system, causing loss of skin sensation, loss of hearing and speech, visual constriction and ataxia. ${ }^{5}$

Scientific programmes have been launched to understand the way mercury contaminates the environment and the following section will review some of the key findings from such programmes. In 2002, the United Nations Environment Programme (UNEP), conducted a global mercury assessment and found that mercury pollutes the environment through its emissions to air and direct release to water and land. Depending on its form, mercury may deposit locally or globally, for instance gaseous elemental mercury has a long atmospheric lifetime, thus it is transported globally to regions far from the emission source. However, gaseous inorganic ionic mercury has a shorter atmospheric lifetime, thus it deposits onto land or water-bodies within approximately 100 to 1000 kilometres from the source. Mercury is persistent in the environment and it circulates between air,

\section{Environmental impact}

This paper assessed environmental mercury contamination and human exposure in communities living in close proximity to a dam. The dam is fed by a river that was contaminated with mercury. Once deposited in the aquatic system, mercury is transformed by microbial action into methyl-mercury, which is soluble, mobile, and rapidly incorporated into aquatic food chains. Methyl-mercury enters the aquatic food chain through ingestion by aquatic species, such as fish. It concentrates as it moves up the food chain, accumulating in fish to levels of between 10000 and 100000 times the concentration of surrounding water. Methyl-mercury exposure to humans is mainly through fish consumption. Thus, this study contributes to an understanding of bioaccumulation and

biomagnification properties of mercury in aquatic environments. 
water, sediments, soil and biota for years. The presence of mercury in the environment poses human health effects. Exposure pathways include, fish consumption, occupational use, dental amalgams and mercury-containing vaccines. ${ }^{1}$

Prior to the United Nations Environment Programme, United States Environmental Protection Agency (US EPA) conducted a study to assess the fate and transport of mercury in the environment. US EPA associated the presence of mercury concentration in air, soil, water and sediments with emissions from anthropogenic combustion and industrial sources. It also linked methyl-mercury concentration in freshwater fish with such sources. ${ }^{6}$ US EPA findings were later emphasized by the Arctic monitoring and assessment programme (AMAP). The AMAP report in 2005, stated that coal combustion, waste incineration and industrial processes were the main sources of mercury pollution worldwide. ${ }^{7}$

In 1990 accounts of occupational exposure to mercury, as well as environmental mercury contamination in the vicinity of a former mercury processing plant (Thor Chemicals Pty Ltd) located in South Africa's KwaZulu-Natal province, were published in local and international media. Thor Chemicals processed mercury waste from international as well as local sources. The reports stated that spent mercury waste was discharged into the Mngceweni River, the source of which is situated in close proximity to the Thor Chemicals plant. ${ }^{8}$ Investigations at the time showed elevated mercury exposure in the workforce, and three of the plant's workers died from mercury poisoning. ${ }^{9}$ Elevated mercury levels were found in sediment samples collected from the Mngceweni River immediately downstream from the plant, ${ }^{10}$ and in fish collected from the local water system. ${ }^{11}$ Mercury levels in hair were below international guideline levels, albeit in a small sample $(n=14) .{ }^{11}$ The authors emphasized that the biomagnification and bioaccumulative properties of mercury could pose an elevated risk of mercury exposure in local communities in the longer term, and advised that a biomonitoring programme be implemented to monitor the situation. ${ }^{11}$

In 2007, nearly two decades after the incident, and thirteen years after mercury processing operations were reportedly discontinued at the plant, a study was conducted to determine downstream environmental mercury concentrations, and levels of mercury exposure in villagers living alongside the Inanda Dam.

\section{Materials and methods}

\subsection{Study area and population}

The study was conducted in the randomly selected villages of Madimeni, Nqetho and Mshazi, located on the banks of the Inanda Dam in the KwaNgcolosi district of South Africa's KwaZulu-Natal province (Fig. 1). The Inanda Dam receives water from the uMgeni River. The Mngceweni River, the source of which is located in close proximity to the former Thor Chemicals plant, is a tributary of the uMgeni River (Fig. 1). The plant is situated in the uMgeni catchment at Cato Ridge between the cities of Pietermaritzburg and Durban. At a distance of 2 to $3 \mathrm{~km}$ from its source, the Mngceweni River joins the uMgeni River, which in turn flows into the Inanda Dam (Fig. 1). ${ }^{11}$ The distance between Thor Chemicals and the Inanda Dam is approximately $35 \mathrm{~km} .^{12}$

One hundred and eighty-nine households from the three villages were randomly selected for inclusion in the study. One adult (of at least 18 years of age, who was most knowledgeable

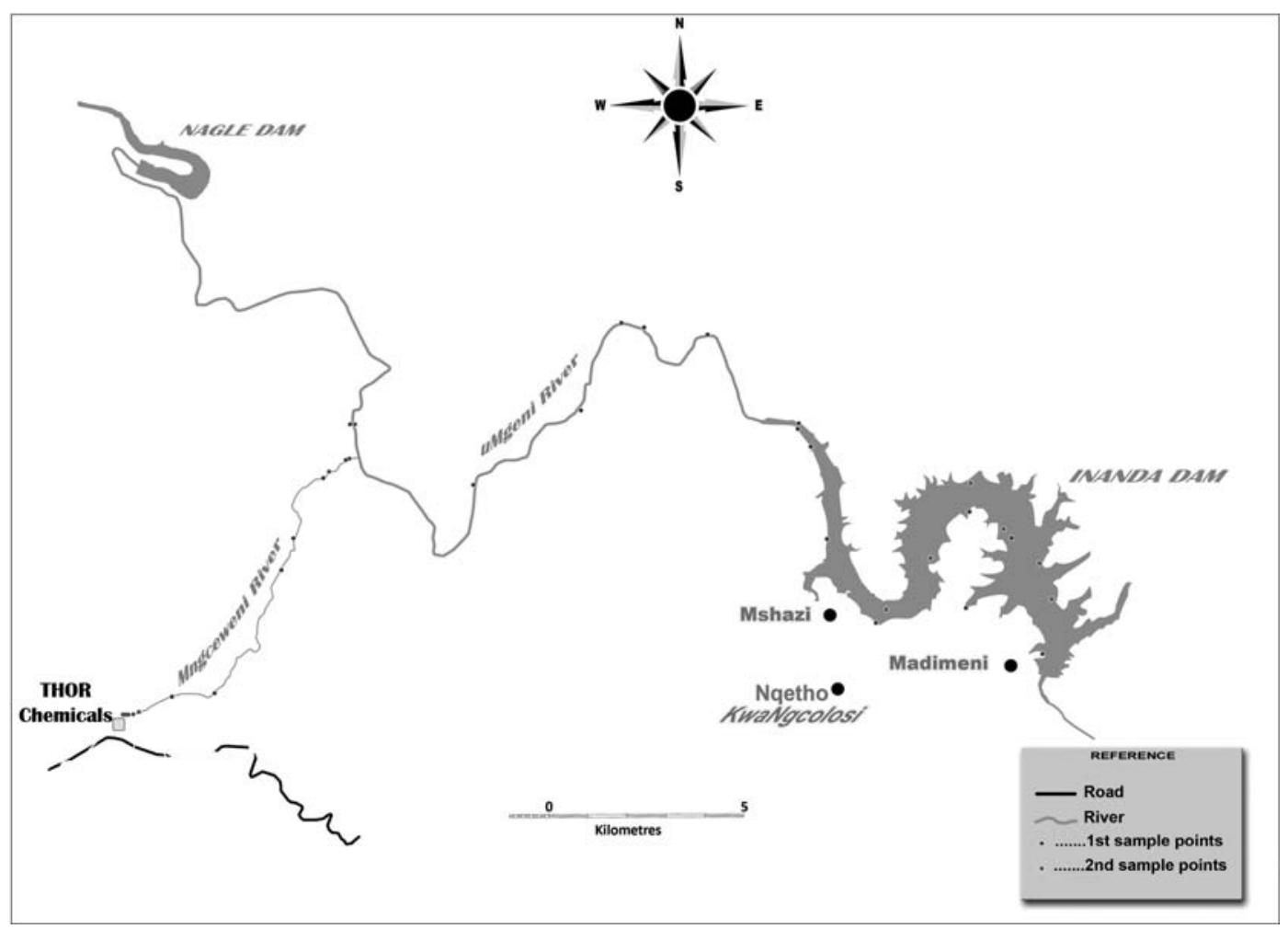

Fig. 1 Sketch map of the study area, showing the study villages, study dam and rivers and the sediment sampling points. 
about the history of the household) from each household agreed to complete a pre-structured questionnaire to obtain information on socio-demography and history of exposure to mercury. A subsample of 86 adults agreed to donate a hair sample for mercury content analysis.

\subsection{Hair sampling}

Hair locks of at least 100 strands of hair (approximately $50 \mathrm{mg}$ ) from 86 study participants were cut from the root of the occipital region of the scalp with stainless-steel scissors and stored at room temperature until analysis. ${ }^{13}$

\subsection{Fish sampling}

Ten fish (catfish and carp species) of varying sizes and lengths (weight range: $0.08-5.5 \mathrm{~kg}$; length range: $29-68 \mathrm{~cm}$ ), were captured from the Inanda Dam by a local fisherman using fishing nets. Cyprinus Carpio Linnaeus, the most common species of Carp in the region, is omnivorous, and thus consumes a wide range of plants and animal matter, mainly by grubbing in sediment. Catfish are piscivores and prey on a wide range of aquatic fauna, including fish. ${ }^{14}$ Each fish sample was sealed in a heavyduty plastic bag, and labelled with the date, site of capture and the type of fish. The fish samples were kept in cooler boxes containing ice, and flown to Johannesburg, where they were kept at -15 degrees Celsius for one day prior to their transportation to the laboratory for analysis.

\subsection{Sediment sampling}

Thirty-seven sediment samples were collected along a path from the source of the Mngceweni River $(n=13)$, along the uMgeni River $(n=10)$ and into the Inanda Dam $(n=14)$ (Fig. 1). Sample collection was commenced at the Inanda Dam and continued in an upstream direction in order to minimise disturbance of the sediment bed, and prevent sample contamination. A small stainless-steel spade was used to collect each sample (500 g) into a plastic sampling bag (acid-cleaned and dried) and sealed. Immediately after sample collection, labels, with the sample code and date of collection written using a waterproof pen, were firmly attached to the plastic sample bags. ${ }^{15}$ The bagged samples were placed in plastic storage crates and transported to the laboratory.

\subsection{Analytical procedures}

The determination of total mercury and methyl-mercury in hair and in fish was conducted using standard analytical techniques and certified standards to validate the mercury content. Total mercury levels were determined using inductive coupled plasma mass spectrometry (ICP-MS) (detection limit $\left.=1.302 \mathrm{ng} \mathrm{g}^{-1}\right)$ and the methyl-mercury levels were determined using gas chromatography-inductive coupled plasma mass spectrometry (GCICP-MS) (detection limit $=1.357 \mathrm{ng} \mathrm{g}^{-1}$ ). The analyses were performed at the Environmental Analytical Chemistry Laboratory of the University of the Witwatersrand in Johannesburg, South Africa. All the hair samples were analysed for total mercury content, however to minimise costs involved in analysis of methyl-mercury from each sample, methyl-mercury concentrations were measured in nine hair samples, three samples from each village. In fish samples, total mercury content was determined in all samples and methyl-mercury content was measured in three samples. Determination of total mercury in sediment samples was undertaken at the Henan Geoanalysis Laboratory in China, using hydride generation-atomic fluorescence spectrometry (HG-AFS-8130) (detection limit $=5 \mathrm{ng} \mathrm{g}^{-1}$ ).

At the laboratory, $400 \mathrm{mg}$ of fish muscle tissue were weighed out and freeze-dried. Thereafter, samples were digested using a mixture of nitric and perchloric acids, and analysed for total mercury using the methods of Lee and Suh (2005). ${ }^{16}$ For methylmercury, $250 \mathrm{mg}$ of freeze-dried muscle tissue were analysed according to Martin-Doimeadios et al., (2002). ${ }^{17}$ A certified reference standard, CRM 463 tuna fish, was used to validate the analytical method, and recovery was between $94.4 \%$ and $97.7 \%$ (average $=95.8 \%$ ).

Hair samples were washed with neutral detergent, water and with acetone. Samples were dried at room temperature, transferred into glass beakers and cut finely. Hair samples of $20 \mathrm{mg}$ (for total mercury) and $10 \mathrm{mg}$ (for methyl mercury) were analysed according to the procedures of Morton et al., (1999).$^{18}$ To confirm the reliability of the methods used, comparative analysis using two different analytical techniques were used for three randomly selected hair samples: ICP-MS that measured total mercury and GC-ICP-MS that performed speciation analysis and measured both inorganic and methyl-mercury fractions. The total mercury content obtained by these two techniques differed by only $3.72 \%$, which confirms the reliability of the methods used.

A day after collection, sediment samples were dried for 14 days at room temperature to prevent mercury loss. Obtained crusts were broken using a jaw crusher, followed by sieving to a size of 75 microns fraction. This pre-preparation was performed at the specialised laboratory of the Council for Geoscience, South Africa. Samples (75 micron fractions) were couriered in air-tight self-sealing bags to Henan Laboratory, China for further processing and analyses. To decompose samples, $0.5 \mathrm{~g}$ of sediment sample each was weighed and $10 \mathrm{ml}$ fresh aqua regia solution $(1+$ $1 \mathrm{~V} / \mathrm{V})$ were added, the mixture was shaken and placed in a heating block for 1.5 hours. After cooling, approximately $5 \mathrm{ml}$ hydrochloric acid (HCL) were added to a decomposed sample to produce a clear solution. Five millilitres of supernatant solution were transferred to a $50 \mathrm{ml}$ beaker and one drop each of $40 \mathrm{~g} \mathrm{~L}^{-1}$ $\mathrm{K}_{2} \mathrm{Cr}_{2} \mathrm{O}_{7}$ and $\mathrm{H}_{2} \mathrm{C}_{2} \mathrm{O}_{4}$ solutions were added and shaken after each addition for 10 minutes. The total mercury concentration was determined using hydride generation-atomic fluorescence spectrometry (Hg-AFS-8130).

To ensure reliability of the method used during sediment analysis, with each batch of 40 sediment samples, two reagent blank samples and 5 GSS reference standards were analysed and the overall recovery was greater than $93 \%$. A serial soil reference material developed by the Institute of Geophysical and Geochemical Exploration (IGGE,) China Geoscience Academy, was used.

\subsection{Statistical analysis}

The STATA package version 10 software (Stata Corp LP, College Station, TX, USA) was used for data entry and analysis. Descriptive statistics were employed to describe the characteristics of each variable in the study population. Thereafter, all the 
Table 1 Concentrations of total mercury (t-Hg) in hair samples

\begin{tabular}{|c|c|c|c|c|}
\hline & $\begin{array}{l}\text { Mshazi } \\
\text { Total mercury/ } \mu \mathrm{g} \mathrm{g}^{-1}\end{array}$ & $\begin{array}{l}\text { Nqetho } \\
\text { Total mercury } / \mu \mathrm{g} \mathrm{g}^{-1}\end{array}$ & $\begin{array}{l}\text { Madimeni } \\
\text { Total mercury/ } \mu \mathrm{g} \mathrm{g}^{-1}\end{array}$ & $\begin{array}{l}\text { Control samples from } \\
\text { Johannesburg } \\
\text { Total mercury } / \mu \mathrm{g} \mathrm{g}^{-1}\end{array}$ \\
\hline Min & 0 & 0 & 0 & 0 \\
\hline $25^{\text {th }}$ percentile & 1.83 & 0.19 & 0.41 & 0.032 \\
\hline Median & 2.46 & 0.81 & 1.20 & 0.037 \\
\hline $75^{\text {th }}$ percentile & 10.07 & 2.1 & 6.06 & 0.075 \\
\hline$\%$ exceeding WHO guideline & $24 \%$ & $12 \%$ & $23 \%$ & $0 \%$ \\
\hline
\end{tabular}

data were recoded into categorical variables. The data on mercury levels in human hair (main outcome variable) were presented in terms of the $25^{\text {th }}$ percentile, median and $75^{\text {th }}$ percentile per village, and categorized into levels above and below the WHO safe mercury limit. The statistical significance of differences in median hair mercury concentration in the three villages was determined using the Kruskal-Wallis non-parametric test. To determine associations between the main outcome variable and each risk factor variable, bivariate logistic regression using two-by-two contingency tables based on the Chi squared $\left(\chi^{2}\right)$ measure was employed.

\section{Results}

Sixty-three percent of the study participants were women. Participants ranged in age from 18 to 80 years (the mean age was 39 years), and had lived in their current dwelling from 1 to 76 years $($ mean $=21$ years). Levels of unemployment were high and educational attainment low. For example, only $20 \%$ were employed and $44 \%$ had either no schooling at all or only some primary school education. None of the participants had obtained a tertiary educational qualification. Those who were employed had mainly menial jobs, for example house cleaning, gardening and road sweeping, as well as child minding. Forty-four percent of the participants regularly (at least weekly) consumed fish from either the uMgeni River or the Inanda Dam. Sixty percent of the participants reported regular consumption of vegetables, which had been cultivated in community gardens along the banks of the Inanda Dam. None of the participants reported past or current occupational exposure to mercury.

The concentrations of mercury in the 86 hair samples ranged from $<0.1$ to $54.8 \mu \mathrm{g} \mathrm{g}^{-1}$ (see Table 1). Mercury concentrations in

Table 2 Total mercury (t-Hg) and methyl-mercury ( $\mathrm{MeHg}$ ) levels in human hair samples

\begin{tabular}{lllll}
\hline Village Name & $\begin{array}{l}\text { Sample } \\
\text { number }\end{array}$ & $\begin{array}{l}\mathrm{t}-\mathrm{Hg} / \mu \mathrm{g} \\
\mathrm{g}^{-1}\end{array}$ & $\begin{array}{l}\mathrm{MeHg} / \mu \mathrm{g} \\
\mathrm{g}^{-1}\end{array}$ & $\begin{array}{l}\mathrm{MeHg} / \mathrm{t}-\mathrm{Hg} \\
(\%)\end{array}$ \\
\hline \multirow{2}{*}{ Mshazi } & $\mathrm{H} 13$ & 6.01 & 5.98 & 100 \\
& $\mathrm{H} 23$ & 1.88 & 1.81 & 96 \\
\multirow{3}{*}{ Nqetho } & $\mathrm{H} 25 \mathrm{a}$ & 1.02 & 0.77 & 75 \\
& $\mathrm{H} 57$ & $\mathrm{nd}$ & $\mathrm{nd}$ & $\mathrm{nd}$ \\
\multirow{4}{*}{ Madimeni } & $\mathrm{H} 61$ & 2.10 & 1.93 & 92 \\
& $\mathrm{H} 66$ & 0.26 & 0.25 & 96 \\
& $\mathrm{H} 126$ & 1.07 & 0.87 & 81 \\
& $\mathrm{H} 158$ & 2.23 & 2.13 & 96 \\
& $\mathrm{H} 177$ & 51.74 & 51.03 & 99 \\
\hline
\end{tabular}

$17 \%$ of samples exceeded the World Health Organisation (WHO) guideline level of $7 \mu \mathrm{g} \mathrm{g}^{-1}{ }^{19}$ The concentrations of mercury in the hair of two study participants exceeded $50 \mu \mathrm{g} \mathrm{g}^{-1}$, which is the WHO guideline level for methyl-mercury intoxication. ${ }^{19}$ The difference in median hair total mercury levels between the three villages $\left(\right.$ Mshazi $\left.=2.46 \mu \mathrm{g} \mathrm{g}^{-1}\right)$, $\left(\right.$ Nqetho $=0.81 \mu \mathrm{g} \mathrm{g}^{-1}$ ) and (Madimeni $\left.=1.20 \mu \mathrm{g} \mathrm{g}^{-1}\right)$ was significant $(p=0.01)$. The ratio of methyl-mercury to total mercury in nine participants selected from the three villages was $75-100 \%$, suggesting mercury contamination through diet (see Table 2). Bivariate analysis showed that vegetable consumption (OR 2.49; CI 0.49-12.66), fish consumption (OR 1.80; CI 0.51-6.30) and low levels of education (OR 1.62; CI 0.46-5.70) were risk factors for elevated hair mercury levels in the study sample.

The concentrations of mercury in the sediment samples ranged from $<0.1$ to $897.5 \mu \mathrm{g} \mathrm{g}^{-1}$ (see Table 3), with the mean and median concentrations respectively equalling 52.83 and $0.09 \mu \mathrm{g} \mathrm{g}^{-1}$. Twenty-two percent $(n=8)$ of the sediment samples had mercury concentrations that exceeded the Severe Effect Level (SEL) of $2 \mu \mathrm{g} \mathrm{g}^{-1}$ adopted by the Ontario Ministry of the Environment, ${ }^{20}$ while mercury concentrations exceeded $50 \mu \mathrm{g} \mathrm{g}^{-1}$ (the level used in The Netherlands to designate soil or sediment as chemical waste) in $19 \%(n=7)$ of the sediment samples. ${ }^{21}$ Table 3 gives the mercury content analysis, broken down by river/dam. As can be seen, all samples with elevated mercury concentrations originated from the Mngceweni River. Sixty-two percent of the thirteen Mngceweni River sediment samples exceeded mercury concentration levels of $2 \mu \mathrm{g} \mathrm{g}^{-1}$ and $10 \mu \mathrm{g} \mathrm{g}^{-1}$, respectively, compared with none in either the uMgeni River or the Inanda Dam samples. The concentration of $10 \mu \mathrm{g} \mathrm{g}^{-1}$ in sediments is

Table 3 Sediment mercury concentrations $\left(\mu \mathrm{g} \mathrm{g}^{-1}\right)$ by river/dam

\begin{tabular}{|c|c|c|c|c|}
\hline & Mngceweni & uMgeni & Inanda & Total \\
\hline & & & & \\
\hline$n$ & 13 & 10 & 14 & 37 \\
\hline Mean & 154.22 & 0.18 & 0.07 & 52.83 \\
\hline Median & 92.27 & 0.05 & 0.04 & 0.09 \\
\hline Standard deviation & 242.99 & 0.25 & 0.07 & 158.88 \\
\hline Minimum value & 0.08 & 0.04 & 0.01 & 0.02 \\
\hline Maximum value & 897.51 & 0.69 & 0.26 & 897.5 \\
\hline $\begin{array}{l}\%>2 \mu \mathrm{g} \mathrm{g}^{-1} \text { (Ontario Severe Effect } \\
\text { Level) }\end{array}$ & $62 \%$ & $0 \%$ & $0 \%$ & $22 \%$ \\
\hline $\begin{array}{l}\%>10 \mu \mathrm{g} \mathrm{g}^{-1} \text { (Remediation Level: } \\
\text { The Netherlands) }\end{array}$ & $62 \%$ & $0 \%$ & $0 \%$ & $22 \%$ \\
\hline $\begin{array}{l}\%>50 \mu \mathrm{g} \mathrm{g}^{-1} \text { (Chemical Waste: } \\
\text { The Netherlands }\end{array}$ & $54 \%$ & $0 \%$ & $0 \%$ & $19 \%$ \\
\hline
\end{tabular}


Table 4 Fish total mercury levels $\left(\mu \mathrm{g} \mathrm{g}^{-1}\right)$ Inanda Dam, Kwazulu-Natal, South Africa

\begin{tabular}{lllllll}
\hline Fish species & \multicolumn{5}{c}{$\begin{array}{c}\text { Standard } \\
\text { Mean }\end{array}$} & Median \\
deviation & Min Max \\
\hline Catfish (Clarias gariepinus $)(n=3)$ & 1.21 & 1.15 & 0.54 & 0.70 & 1.78 \\
Carp (Cyprinus carpio) $(n=7)$ & 0.44 & 0.34 & 0.20 & 0.26 & 0.79 \\
Total $(n=10)$ & 0.67 & 0.55 & 0.48 & 0.26 & 1.78 \\
\hline
\end{tabular}

a level at which remedial action is required. ${ }^{21}$ Fifty-four percent of the Mngceweni River sediment samples exceeded $50 \mu \mathrm{g} \mathrm{g}^{-1}$.

The total mercury concentration level in the ten fish samples ranged from 0.26 to $1.78 \mu \mathrm{g} \mathrm{g} \mathrm{g}^{-1}$, with the mean and median equalling 0.67 and $0.55 \mu \mathrm{g} \mathrm{g}^{-1}$, respectively (see Table 4). Furthermore, three fish samples were also analysed for methylmercury content and the results ranged from 0.83 to $1.77 \mu \mathrm{g} \mathrm{g}^{-1}$, with the mean and median equalling 1.25 and $1.15 \mu \mathrm{g} \mathrm{g}^{-1}$, respectively. Fifty percent $(n=5)$ of the fish samples were found to have mercury concentrations that exceeded the World Health Organization (WHO) guideline level of $0.5 \mu \mathrm{g} \mathrm{g}^{-1} .^{19}$

\section{Discussion}

This study has shown that communities living alongside the Inanda Dam in South Africa's KwaZulu-Natal province are at risk of exposure to mercury. Hair mercury concentrations were elevated above the WHO guideline level in $17 \%$ of the study sample. In two of the study participants, hair mercury concentrations were sufficiently elevated to be within a range of concern described by WHO as mercury intoxication. The hair mercury concentrations in this study group were considerably elevated compared with the findings from recent studies conducted elsewhere. For example, women health facility users in Korea had a mean hair mercury concentration of $0.906 \mu \mathrm{g} \mathrm{g}^{-122}$ and women aged 16 to 49 years $(n=1726)$ in the USA National Health and Nutrition Examination Survey (NHANES) had a mean hair mercury concentration of $0.47 \mu \mathrm{g} \mathrm{g}^{-1}$. $^{23}$

Statistical analyses pointed to food (fish as well as vegetables cultivated along the banks of the Inanda Dam) being a likely pathway of exposure to mercury in this community. This statistical observation was supported by the elevated concentrations of mercury determined in $50 \%$ of the fish captured from the Inanda Dam, albeit in a relatively small sample $(n=10)$. None of the participants reported past or current occupational exposure to mercury, leading to the conclusion that occupational mercury exposure was unlikely.

Multiple sources could have contributed to the mercury exposure observed in the study communities. For example, it is possible that mercury released into the environment from the former Thor Chemicals plant has been assimilated into river and dam sediments, and converted to methyl-mercury through microbial activity. ${ }^{24}$ In this regard, it is noteworthy that highly elevated concentrations of mercury were found in the current study, in sediment sampled from the Mngceweni River at points in closest proximity to the former Thor Chemicals plant. Elevated concentrations of mercury in fish have been demonstrated up to three or more decades following terrestrial flooding associated with reservoir construction. ${ }^{25}$ The Inanda Dam was created through such a flooding process in 1988, and it is possible that the elevated exposure to mercury observed here, is attributable to this process. Other potential contributing factors or processes include sand mining activities reported within the aquatic system (which could be playing a role in disturbing mercury assimilated into the sediment beds), local industries and air deposition from local or distant mercury-related activities.

Given the known persistence, and bioaccumulative as well as biomagnification properties, of mercury in an aquatic system, ${ }^{6}$ and the serious health risks, it is of considerable concern that no comprehensive public health monitoring program seems to have been implemented following the creation of the Inanda Dam or the Thor chemicals contamination incident. In respect of the latter, specific warnings of long-term human health risks, and recommendations for environmental and biomonitoring (including human exposure) programmes recommended by earlier researchers ${ }^{10-12}$ appear not to have been heeded. It is similarly troubling that remediation measures, if any, implemented over the past decade appear to have been of limited effect in bringing mercury seepage from the plant to an end, and thus protecting downstream food chains and communities from mercury exposure.

Notwithstanding its relatively small scale, this study has determined that the focus communities, and potentially other communities located alongside the dam, are at risk of exposure to mercury. Further research work is required to investigate the environment and human health implications of mercury exposure in this setting. Furthermore, identification of the source of the mercury and implementation of environmental remediation measures are required to reduce the levels of mercury in the local ecosystem and to prevent further human exposure. The design and implementation of long-term environment and health surveillance programmes is important, as is the immediate implementation of community mercury hazard awareness campaigns. Further short-term measures may include local fish and vegetable consumption advisories, especially in respect to children and pregnant women.

\section{Acknowledgements}

The authors thank the South African Medical Research Council, the South African Department of Science \& Technology, the South African Council for Geoscience and London South Bank University for support in this study. The study participants are also thanked for the important role they played in this work.

\section{References}

1 UNEP (United Nations Environment Programme), Global mercury assessment, UNEP, Geneva, 2002.

2 F. Zahir, S. J. Rizwi, S. K. Haq and R. H. Khan, Environ. Toxicol. Pharmacol., 2005, 20, 351-360.

3 G. J. Myers, P. W. Davidson, C. Cox, C. F. Shamlaye, D. Palumbo, E. Cernichiari, J. Sloane-Reeves, G. E. Wilding, J. Kost, L. Huang and T. W. Clarkson, Lancet, 2003, 361, 1686-1692.

4 National Research Council. Toxicological effects of methylmercury, Board on environmental studies and toxicology, Commission on Life Sciences. Washington, DC, National Academy Press, 2000.

5 L. Knobeloch, H. A. Anderson, P. Imm, D. Peters and A. Smith, Environ. Res., 2005, 97, 220-227.

6 U.S. EPA, Mercury Study Report to Congress, Vol. I EPA-452/R-97003, United States Environmental Protection Agency, 1997.

7 AMAP Assessment 2002: Heavy Metals in the Arctic. Arctic Monitoring and Assessment Programme (AMAP), Oslo, Norway, 2005.

8 L. Clarke, Daily News, 23 March, 1994. 
9 H. Ward, Corporate accountability in search of a treaty? Some insights from foreign direct liability. The Royal Institute of International Affairs, sustainable development programme, http:// www.chathamhouse.org.uk/publications/papers/view/-/id/56/, 2002.

10 P. Johnston, R. Stringer, M. C. French and J. Vallette, Bull. Environ. Contam. Toxicol., 1991, 46, 74-78.

11 J. Oosthuizen and R. Ehrlich, Int. J. Environ. Health Res., 2001, 11, 41-50.

12 G. J. Barratt \& J. Combrink, Water Institute of South Africa. Water SA Special Edition: WISA Proceedings, ISBN 1-86845-946-2, 2002.

13 H. Kehrig, O. Malm, H. Akagi, J. R. D. Guimarães and J. P. M. Torres, Environ. Res., 1998, 77, 84-90.

14 P. H. Skelton, A complete guide to the freshwater fishes of Southern Africa. Halfway House, South Africa, Southern Life Book Publishers, 1993.

15 L. R. Shelton \& P. D. Capel, Guidelines for collecting and processing samples of stream bed sediments for analysis of trace elements and organic contaminants for the national water-quality assessment programme, U S Geological Survey Open-File Report 94-458, Sacramento California, 1994

16 S. H. Lee and J. K. Suh, Microchem. J., 2005, 80, 233-236.

17 R. C. Martin-Doimeadios, E. Krupp, D. Amouroux and O. F. Donard, Anal. Chem., 2002, 74(11), 2505-2512.
18 J. Morton, V. A. Carolan and P. H. E. Gardiner, J. Anal. At. Spectrom., 2002, 14, 127-129.

19 WHO (World Health Organisation), Environmental Health Criteria 101: Methylmercury. Geneva, 1990.

20 Ontario Ministry of the Environment, Ontario's sediment quality guidelines as provided in Guidelines for Identifying, Assessing and Managing Contaminated Sediments in Ontario: An integrated approach, http://www.ene.gov.on.ca/en/publications/forms/index. php\#resources, 2008.

21 W. J. Th. Van Gemert, J. Quakernaat, H. J. Van Veen. in Environmental management of solid wastes: Dredged material and mine tailings ed. W. Salomons and U. Forstner, Springer-Verlag, New York, 1988.

22 S. A. Kim, C. K. Jeon and D. M. Paek, Sci. Total Environ., 2008, 402(1), 36-42.

23 M. A. McDowell, C. F. Dillon, J. Osterloh, P. M. Bolger, E. Pellizzari, R. Fernando, R. Montes de Oca, S. E Schober, T. Sinks, R. L. Jones and K. R. Mahaffey, Environ Health Perspect., 2004, 112(11), 1165-71.

24 T. A. Jackson, Water Pollution Res. Council J., 1993, 28, 177-216.

25 M. Mailman, L. Stepnuk, N. Cicek and R. A. Bodaly, Sci. Total Environ., 2006, 368(1), 224-235. 